\title{
An Introduction:
}

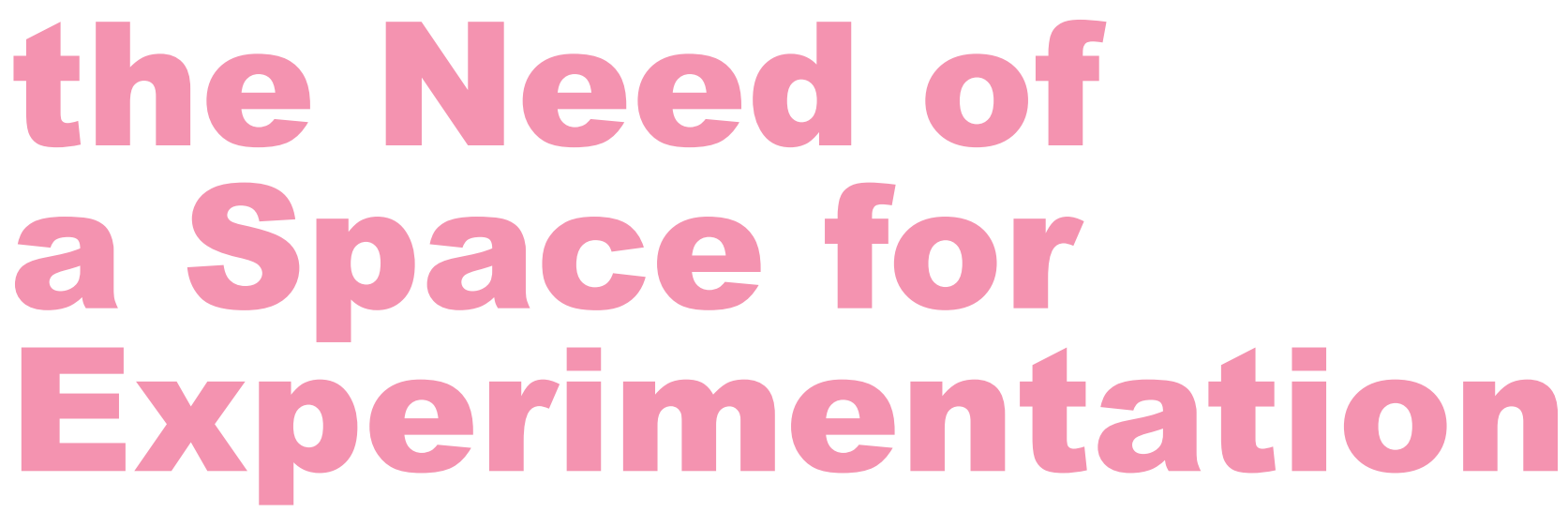

\section{Nobile, Maria Luna ${ }^{1}$}

${ }^{1}$ Umeå School of Architecture / Umeå University, Sweden https://orcid.org/0000-0001-8958-2999

maria.nobile@umu.se

Citation: Nobile, M.L. (2021). An Introduction: the Need of a Space for Experimentation. UOU scientific journal

\#01, 14-21.

ISSN: 2697-1518. https://doi.org/10.14198/UOU.2021.1.02

This document is under a Creative Commons Attribution 4.0 International license (CC BY 4.0) 
We are living in times of urgency.

In the current year, we have been forced to translate and discover new values, both in Education and Research in Architecture. While we have had to rethink the space of the room and the boundaries of our individual space in between four walls, a floor and a ceiling, and the world outside, other typologies of spaces have been imagined and -all of a sudden- this hybrid space between the physical and the digital space became a reality. Therefore, in this context, the notion of Commons, in its wide acceptation, has been helping us to define a new typology of space, starting from the space of the classroom.

The notion of space has been changing immediately because of the pandemic, forcing us to consider the virtual dimension as a new possibility to interweave the private, public and common aspects of our lives and interconnect them in the definition of a Common Place. This immediately changed the notion of relationships, underlining the value of the notion of community and exchange, removing the existing boundaries and bringing us into the future.

In this Common Place,

\section{UNIVERSITY of Universities}

has been designed with the idea of sharing an international staff of academics with their own background knowledge and research with students coming from different countries, improving the internationalization, opening the borders, travelling without moving, testing and designing a curriculum towards another future for the academia and looking forward to a professional environment that will be slightly different from the one that we already know.

As stated in the concept of the project, UNIVERSITY of Universities (UOU) was founded in July 2020 as an experimental Architecture Programme in the Design Studio for the academic year $2020 / 21$ in the different schools of architecture involved. It is in the intention of moving beyond the virtual lectures, crits and tutorials, in search of new exercises that not only re-define the pedagogical approach to the discipline, but also gives us the opportunity of re-defining the basis of a new Programme in the Architectural Education. (UOU Project, 2020)

\section{UNIVERSITY of Universities is} an open and collective space, where the rules are defined by the community of students and teachers involved in it. It is an open and democratic network that occupies a space that has no boundaries and that does not belong to a specific country or city.

As the ILAUD ${ }^{1}$ Residential Course in Architecture and Urbanism - established by Giancarlo De Carlo in Urbino in September 1976 - was conceived as an itinerant and open alternative to the traditional education of the young architects, so UOU can be seen as a powerful machine to underline the potential of the "laboratory" as the space (material or immaterial) where this energy can be produced.
Indeed, looking at what is UOU, our mind goes immediately to the ILAUD founded by Giancarlo De Carlo in the 70's. The main intentions of ILAUD highlighted by Giancarlo De Carlo (ILAUD Yearbook 1977), have been to create an international network of students and professors among different Universities in Europe, to experiment with new methodologies and techniques for the architectural design, to provide the space for researchers and teachers in the academia to have the opportunity to compare their didactic approaches, and opening a channel for intercultural exchange between universities. At ILAUD, students were invited from different schools of Architecture in Europe $^{2}$, English was chosen as a common language of communication, and a yearbook has been the tool both to collect the reflections that occurred and as way of communicating outside what happened inside the classroom.

The different backgrounds of students, coming from a highly diverse range of geographic and cultural contexts, resulted in different approaches and methods, and the evidence of the importance of opening a debate on the new role of the architects at that time (ILAUD Yearbook 1977).

In order to achieve this aim, the school provided specific tools for developing a critical consciousness. Magazines, for instance, were considered by De Carlo a fundamental tool to appreciate different approaches to the architectural debate. What we have definitely learned 
from this experience, after more than 40 years, is the necessity of an intercultural way of learning and the endless possibilities that this way of thinking is opening for future architects. But what are the common values that can be enhanced and adapted to the needs of current society? How can we fix and transmit what we have learned and experienced during this academic year?

\section{The UOU scientific journal}

was born in Sweden in November 2020 in the framework of a research seminar on the topic of International Research hosted by the Umeå School of Architecture. This addressed the need for providing a place for all the research from the enormous production of reflections and experiments that were part of the UOU project during the autumn semester involving a team of academics from all over Europe. The Journal has been designed as a space to host reflection on topics linked to contemporary debates in Architecture that are at the center of the discourse on the education of future architects, made possible by the opportunities that have emerged from the experience of exchange between the European Universities on the question of the Internationalization of Teaching Architecture in a time of pandemic. In this sense, the research is a tool to reinforce the education, and the education acts as a testing tool and space for experimentation. This experiment gave us the possibility of enhancing the value of the international exchange between cultures and empowering education in architecture thanks to the opportunity of sharing the same common space over enormous distance and different time zones. The reflection on the notion of commons from now on will be enriched by the experience of pushing the limits of time and space and rethinking the notion of values in an innovative and unprejudiced way.

An ATLAS of possibilities, both here and now.

\section{The UOU scientific journal} includes researchers' and practitioners' contributions in the form of Articles, that are the core of this Journal, and a reflection on education including student's contributions in the form of Projects in the section ATLAS. The call for this first issue of the journal opened with a reflection on the work of two architects that have been an inspiration for this work, and their texts that are currently on my desk: Giancarlo De Carlo as the author of Architecture of Participation, and Ralph Erskine as the author of Democratic Architecture, with the intention of reflecting on the connections between their lives and researches and looking at the impact of their way of using practice as a tool for testing the theoretical approach to the discipline, as well as the idea of trusting in collaborations.

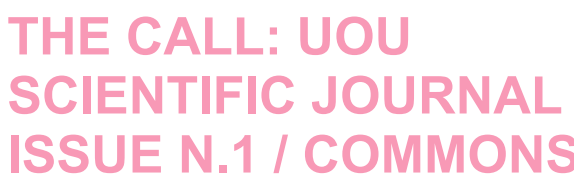

In 1982 the English-Swedish architect Ralph Erskine, opened a lecture by reflecting on the definition of "Architecture as the Art of Building Communities"3. His point of view, which led to a more radical way of considering the role of the architect in society, can be considered as the heritage from the main intention shared by Team 10 during the CIAM in 1959 in Otterlo with Aldo van Eyck, Giancarlo De Carlo, José Antonio Coderch - above the others - while introducing the notion of Democratic Architecture and Architecture of Participation.

With the escalation of the climate crisis at the present time, social inequities and political divergence, the general concern about access to natural and common resources, including space, all this is leading architects and planners to reconsider the notion of values in claiming their collective role towards the definition of a new right to the city ${ }^{4}$. The pandemic has opened a new scenario in which the notion of communing and sharing is assuming a new value and defining new spaces. How can architecture respond to social challenges and climate crisis? Where is the limit of architecture as a discipline in facing the human condition in relation to the scale of the impact on nature? What is the role of architects in response to social and spatial inequalities? What impact can the notion of Commons have on the transformation of cities? And what agency must designers have in contributing to such a transition in the current condition of Urgency? In this framework Commons, the first Issue of the UOU 


\section{The Call: \\ Commons*}

\section{*The use of the term}

Commons might be

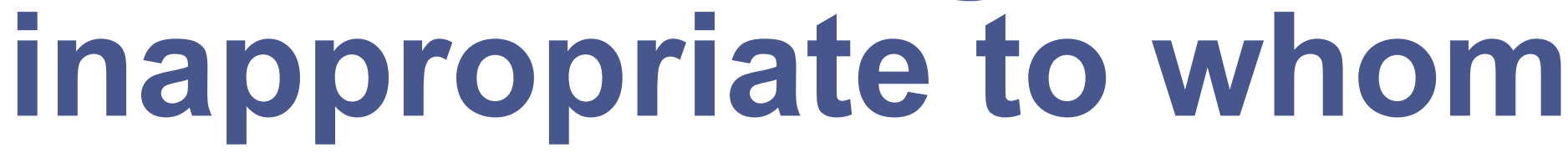

reading this journal

is not ready for

adventures.

scientific journal, aims to redefine the notion of values in relation to material and innovative practices from an unprejudiced aspect.

In England, the word "commons" is generally associated with the Enclosure Acts of the late 18th and early 19th centuries. Commons had existed in the countryside since time immemorial - open grassland, wide roadside verges and heathland on which small farmers and peasants had the right to graze their animals. Enclosure was associated with the rise of modern science in the Age of Enlightenment which impacted on farming by what became known as 'improvement'. Improvement was inextricably linked to capitalism, which was becoming entrenched and its grip extensive. Typically, the main landowners of a parish would pursue enclosure of common land through a particular Act of Parliament and, if passed, commissioners would be appointed to carry it out. Parliament was dominated by landowning aristocracy and the church, and commissioners were big landowners and farmers from outside the village who were engaged to turn the commons into fields, which were then acquired by large landowners. Access to commons, and woods was essential to the survival of the peasant and small farmer with 'rights of common' to graze their cows and sheep. Although this more scientific approach to farming might appear to be a logical extension of past changes, it was in reality a quasi-legalized land grab by landowning classes over the rights of the common people. ${ }^{5}$

For the reader of this Journal the notion of Commons translated in our urban (and digital) environments is to be conceived more as collective production of resources and spaces in general - material or immaterial - rather than with the resources themselves. 
This opens a reflection on the process of spatial organization in the relations between production, ownership and access to these resources, with an open eye on the effect of the Pandemic.

This call for articles aims at exploring the notion of Commons in the field of research in architecture and urbanism along three axes of investigation.

\section{AGENCY: PRACTICES AND GEOGRAPHIES OF COMMON PLACES}

\section{Practices}

One of the urgent questions in architecture is: are we building or making places? This call invites the authors to reflect on the possibilities for a place to become the scenario of new and inventive practices that generate architectural processes of value.

This means to consider the territory as a whole, highlighting initiatives both in the social and political realm that embody a certain spirit of experimentation and with the infinite possibilities related to the specificity of architecture itself: quality of spaces, relation to context, adaptability, flexibility, openness. An Atlas of pioneering places ${ }^{6}$ that explore and experiment through collective processes the notion of building communities in a specific context and place.

\section{Geographies}

The process of mapping extends and enriches our interaction with the specific conditions of a site and its atmosphere. Can the perception of the users allow us to understand and experience the unique characteristics of a specific place? The 'agency' of the map, is that which exploits the research to identify, decode and create the potential of possibilities for a specific place and to define the foundation for a future transformation ${ }^{7}$. If mapping is understood, not as a process of representing geographies or ideas, but as a tool for research and translating into action, how can we as architects effect the way these geographies and ideas are manipulated?

\section{HYPERSPACE: TECTONICS AND HYBRIDS OF COMMON ELEMENTS}

\section{Tectonics}

Cities are often judged by their relationships within society. Under these novel circumstances, what the experts are looking for is a necessary change in architecture more than to architects themselves. Without a doubt, it is time to question the single authorship of the future of Architecture: more than ever, as a discipline, it cannot continue being taught singularly, nor on a local level.

How can the Tectonic as a representation of authorship in architecture recapture its link to the social context and common values? How can the fundamental elements ${ }^{8}$ incorporate and translate the needs for a radical change in the definition of a new role for the architect in a future society?

\section{Hybrids}

Architecture, open and expansive in nature, has explored unlikely interactions and projected hybrids with unpredictable results. The notion of bigamy ${ }^{9}$ for example, is based on the evidence that multiple elements that apparently don't fit together can be merged together to create a new creation or genre. We have the possibility of building the world that we want to inhabit. This is a positioning that will allow us to experiment with new parameters in architecture, opening the path to new ideas that previously seemed impossible or unknown. In this sense, the notion of commons intersects with the definition of hybridity in the discovery of innovative and unprejudiced techniques and materials for defining new kinds of common material and immaterial spaces and explorations. What are the disciplines involved in this interaction? How can common data and digital commons drive the material explorations in architecture?

\section{COSMOS: MEANING AND VALUES OF COMMON ECOLOGIES}

\section{Meanings}

The architect is a storyteller. What would architecture be without a story? We suggest it would not be architecture. But to tell a story we need a language in which to communicate and we need to specify the actors and their movement in the space. What does it mean to imagine and, indeed, experience a space without seeing it? What is the 
common language that enables architecture to be perceived, in terms of knowledge and interaction, within the place itself? How can imaginaries ${ }^{10}$ be conceived and built by the living inhabitants through the definitions of common values overcoming the cultural identities and boundaries?

\section{Values}

The city and, at a micro scale, the building can be explored as a mosaic of spaces defined by the patterns of events which we experience in it ${ }^{11}$. The pandemic offered us a chance of enhancing new values, not only in terms of relationship between human beings, but enabling us to discover and redefine the notion of inception spaces, undetermined spaces, third places, and to determine the importance of nature in the design of our everyday life spaces. But not only this: for in a sense the traditional notion of common ecology disrupts the basic values of dwelling, a room, an apartment, a city. What is the role of the undetermined spaces in the city, both in terms of nature and dwellings? Can architecture be open to the unplanned, and highlight the value of the inhabitants' role in defining a flexible notion of dwelling?

\section{ECHOES: \\ ARCHITECTURE AND COMMONS, TOWARDS A NEW ROLE FOR THE ARCHITECTS OF THE FUTURE.}

The potential of an international call for articles lies mainly in its possibility of it being interpreted by many different voices and languages. As a result, the first call for articles of the UOU Scientific Journal has seen contributions from researchers and practitioners bringing their own original research and projects aiming to interpret the notion of Commons as a way of understanding the value of an architecture which is no longer hiding behind the definition of authorship that has distinguished the role of the architect for decades. The introduction by the coordinator of the UOU Project, Javier Sánchez Merina, is leading us to an unpredictable path, which from July 2020 has been a continuous process of discovery towards new possible explorations. The contribution shared from Joaquín Alvado started from a conversation within the members of the editorial board, and was enriched by the contribution of Mike Devereux and Maria Hadjisoteriou on the future of education and practice in architecture.

It is more and more evident that we are facing new possibilities in the of way of conceiving architecture, overcoming the boundaries of the disciplines and learning from the specificity of our cities and cultural values where the discipline of architecture needs to recapture its political role.

The section "Interpretations" bring us onto a journey that uses the existing literature on the topic of Urban Commons as a way to reflect upon new paths of research. In this, the author Francesco Caneschi introduces the notion of temporariness as a material for an architecture of becoming the scenery of multiple interactions between people and places, opening a reflection on possible kind of architectures, where typologies are replaced by "Prototypes" that experiment with new materials and actions. This is the case of Marie Roels' proposal for the Rhodo Workhome, an experimental project in collaboration with $\mathrm{KU}$ Louvain and the city of Ghent, offering new possible meanings and functions. This echoes the work of Maria José Marcos with her Portable Ecologies recently exhibited in the Spanish

Pavilion at the 17th Architecture Biennale of Venice, which works with traditional functions but innovative responses to the urgent need to adapt existing spaces to the current condition - rethinking the spaces for education - as in the project by Bruna Sigillo for the Coccapani Planetary Garden, winner of the competition Next Landmark 2020 launched by Iris Ceramiche and Floornature.

The contribution of

TAM Associati, with the experimental project $\mathrm{H} 2 \mathrm{OS}$ anti-desertification eco-village in Senegal, includes one of the reflections on the vision of architecture that the founders, Simone Sfriso, Raoul Pantaleo and Massimo Lepore have been testing through their extensive work. In this project, the architecture is conceived as a device that serves the community, with the proposition of Taking care of people and places, principles and resources, as expressed in an exemplary way in the Italian Pavilion in the 15th Architecture Biennale of Venice, curated by TAM Associati on the topic of 
Common good in Architecture.

While these contributions are re-defining the agency of architecture, the contribution included in the section "Experiments" by Emma Davies, compares the approach of two European countries to tradition and the value of Self Build construction as a possibility for an architecture of the future in specific contexts and in the framework of a specific field of research. And on the same path, the contribution by Marcin Kolakowski, based on his comprehensive experience in research and education of Low-Tech, opens the section related to "Interferences" with other disciplines, in this case where Psychoanalysis is used as a key to understand and translate architectural concepts dealing with the idea of values and meaning of common ecologies. The Peruvian case presented by Bruno Chichizola conducts us through a reflection upon the actual impact of the pandemic on the use of public/private spaces in the urban environment, using the ethnographic method as a way to understand and test the theoretical framework on cosmopolitism.

Reflection on the research into pedagogy in architecture is expressed through the contribution from other Schools of Architecture who have shared their pedagogical practices and experiences with us, through analyses of the notion of Commons in the contemporary city. In the case of a group including Orfina Fatigato, Viviana Saitto, Gennaro Finale, Vittoria di
Giulio and Mario Galterisi of the Department of Architecture of the University of Naples Federico II, this involved rethinking the neighborhood of Poplar in East London, specifically questioning the notion of authorship and values in the Robin Hood Gardens housing project. Similarly, the contribution from Eskişehir Technical University, by Nuran Özaslan, Fatma Kolsal and Sevgin Aysu Balkan, examines the role of Nature in the interpretation of the new commons through three experimental Design Studios.

A special place in our ATLAS is given to the contributions of a selection of works from the two week workshop held during the UOU Fall Semester 2020. These include a reflection on reactivation of abandoned places and focusing primarily on a new understanding of the role of architects in a future society, dealing more and more with participatory design tools and with the reuse of existing buildings and interpreting the notion of social and environmental sustainability. A window was opened towards the future where the imaginary landscapes developed by our students - and by the students who have answered the call - with unexpected results of reflections shared in this short Workshop lead by Marie Kraft and myself and accompanied by our UOU colleagues. In this section, the projects of the students are to be considered as a test bed for our work and reflections as researchers, practitioners and educators.

We are living in times of urgency. And it is with this urgency of generating new ideas we, as architects, are finding our places for new opportunities, claiming our place, acting in the common sphere and reinforcing the boundaries of our discipline, while dealing with the need of continuously connecting with other fields of research and studies.

\section{REFERENCES}

\section{ILAUD - De Carlo}

2. Escuela Técnica Superior de Arquitectura of Barcelona, the Katholieke Universiteit of Leuven, the Massachusetts Institute of Technology, the Oslo School of Architecture, The University of Urbino and the Eidgenossische Technische Hochescule of Zurich.

3. R.Erskine, Democratic

Architecture, the Univeral and Useful Art, in: RSA Journal, September 1982, London.

4. H.Lefebrve, Le Droit à la Ville, Points, Paris 1968.

5. A paragraph on the meaning of the concept "Commons" has been added to the Call for articles by Trevor Garnham, our Editor proof-reader that has been a valuable contributor to the work of this Journal.

6. Encore Hereux, Infinite Places (Lieux Infinis) - Constructing Buildings Or Places?, Publisher Editions B42, 2018.

7. J.Corner, The Agency of Mapping. Speculations, Critiques and Inventions, 2011.

8. R.Koolhaas, AMO, Harvard GSD, Elements of Architecture, Tashen, 2018.

9. Byarke Ingels Group, Yes is more. An Archicomic on Architectural Evolution, Tashen, 2018.

10. R.Barthes, Le Degré zéro de l'écriture suivi de Nouveaux essais critiques, Editions du Seuil, Paris 1977.

11. C.Alexander, The timeless way of building, New York, Oxford University Press, 1979 


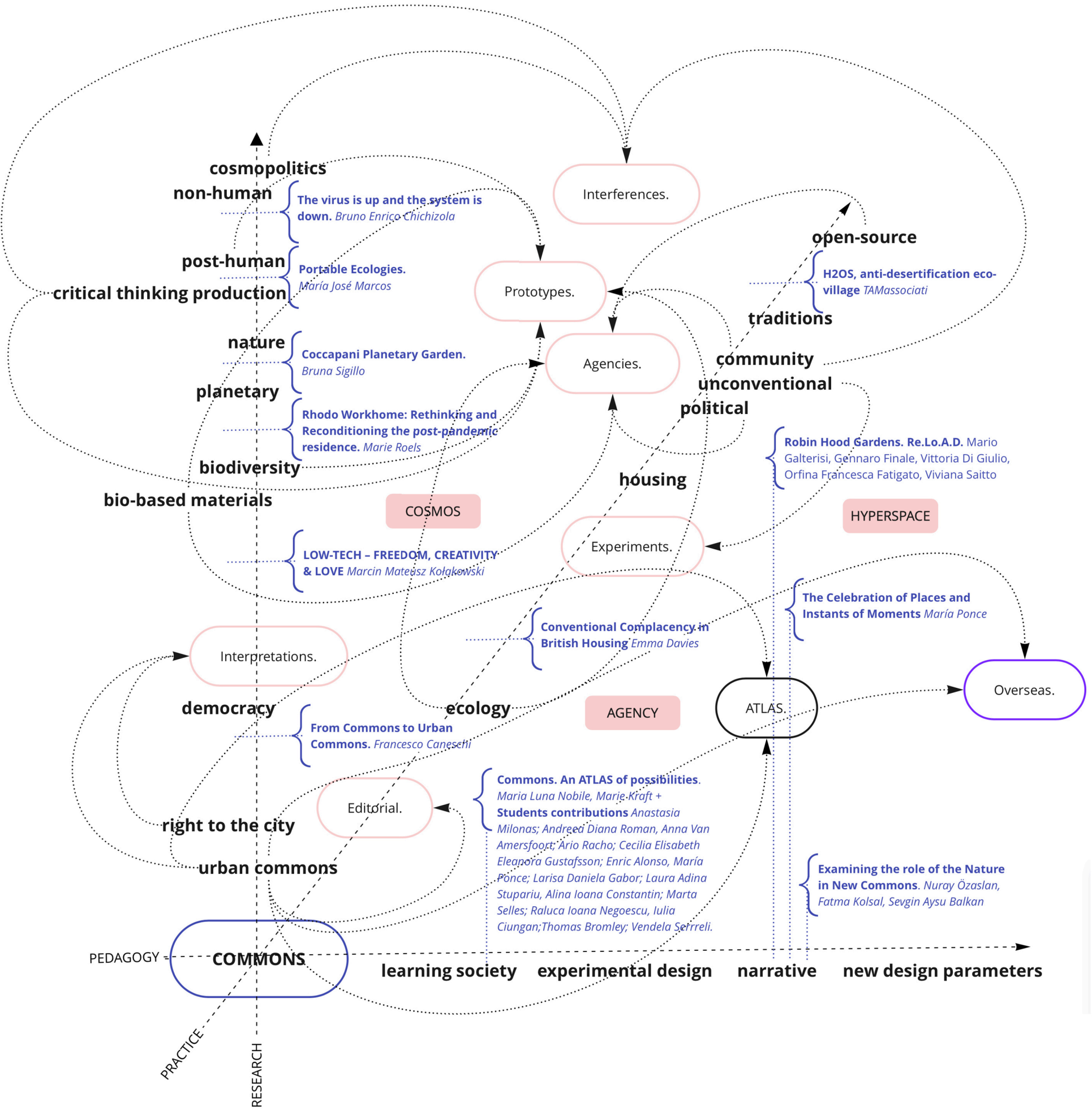

